\section{The genetics of primary nocturnal enuresis: inheritance and suggestion of a second major gene on chromosome $12 \mathrm{q}$}

\author{
Henrik Arnell, Kelm Hjälmås, Martin Jägervall, Göran Läckgren, Arne Stenberg, \\ Bengt Bengtsson, Christer Wassén, Tesfai Emahazion, Göran Annerén, Ulf Pettersson, \\ Mats Sundvall, Niklas Dahl
}

\begin{abstract}
Primary nocturnal enuresis (PNE), or bedwetting at night, affects approximately $10 \%$ of 6 year old children. Genetic components contribute to the pathogenesis and recently one locus was assigned to chromosome 13q. We evaluated the genetic factors and the pattern of inheritance for PNE in 392 families. Dominant transmission was observed in $43 \%$ and an apparent recessive mode of inheritance was observed in $9 \%$ of the families. Among the 392 probands the ratio of males to females was 3:1 indicating sex linked or sex influenced factors. Linkage to candidate regions was tested in 16 larger families segregating for autosomal dominant PNE. A gene for PNE was excluded from chromosome 13q in 11 families, whereas linkage to the interval D13S263D13S291 was suggested $(Z \max =2.1)$ in three families. Further linkage analyses excluded about $1 / 3$ of the genome at a 10 $c M$ resolution except the region around D12S80 on chromosome $12 \mathrm{q}$ that showed a positive two point lod score in six of the families $(Z \max =4.2)$. This locus remains suggestive because the material was not sufficiently large to give evidence for heterogeneity. Our pedigree analysis indicates that major genes are involved in a large proportion of PNE families and the linkage results suggest that such a gene is located on chromosome 12q.

(f Med Genet 1997;34:360-365)
\end{abstract}

Keywords: primary nocturnal enuresis; inheritance; linkage analysis; heterogeneity

Department of Paediatric Surgery, University of Uppsala, Sweden

G Läckgren

A Stenberg

Department of Medical Genetics, University of Uppsala, Sweden

U Pettersson

M Sundvall

Correspondence to Dr Dahl.

Received 28 August 1996 Revised version accepted for publication 25 November 1996

Nocturnal enuresis (McKusick 600631) is one of the most common diagnoses in a paediatric clinic, affecting $5-15 \%$ of 7 year old children. ${ }^{1-6}$ The spontaneous cure rate is about $15 \%$ per year and at the age of 16 years $1-2 \%$ of patients are still enuretic and remain so into adulthood. ${ }^{7}$

Genetic factors have long been recognised in enuresis and familial clustering has been observed in several studies. ${ }^{128-10}$ At least $15 \%$ of the cases are sporadic, but previous reports indicate that the majority $(>50 \%$ ) have a family history of enuresis with different patterns of inheritance. Sporadic and inherited PNE share the same clinical picture and yet these groups may be genetically heterogeneous. Heterogene- ity is substantiated by the observation that children with inherited PNE respond better to pharmacological treatment with the synthetic vasopressin analogue desmopressin acetate. ${ }^{11}$

In contrast, secondary enuresis (onset of enuresis after a dry period of six months or more) does not respond as well to treatment with desmopressin. The causes of secondary enuresis include neurological dysfunction, urogenital malformations, infections, and psychological factors. ${ }^{12} 13$

Although familial PNE probably arises from polygenic inheritance, analysis of a large number of families may enable the identification of major susceptibility loci. Recently, linkage analysis with polymorphic markers identified a locus predisposing to PNE, assigned ENUR1, in a proportion of Danish families. ${ }^{14}$ The gene resides in a $4 \mathrm{cM}$ interval flanked by markers D13S263 and D13S291 on chromosome $13 \mathrm{q}$.

In a clinical and genetic study we examined two aspects of PNE. First, we investigated the genetic predisposition to PNE in 392 cases by recording family history of enuresis. Second, we performed linkage analysis in 16 families segregating for dominant PNE.

\section{Materials and methods}

PATIENTS

In a continuing Swedish multicentre study, ${ }^{15}$ 392 children ( 291 boys and 101 girls) older than 6 years were identified. All showed a severe form of PNE including $\geq 10$ wet nights out of 28 and absence of a dry period $>3$ months. Concomitant neurological or urological dysfunction associated with PNE was excluded. Evaluation of each patient included physical examination and urine analysis.

A detailed family history was recorded in

each case in order to determine the presence of familial PNE as defined by any close relative with PNE beyond the age of 6 years. The parents of affected probands underwent a structured interview with specific questions regarding the onset, frequency, and cessation of bedwetting. Direct contact was made with the relatives when the information from the parents indicated a positive family history for PNE. The diagnosis among second and third degree relatives was ascertained, or excluded, with the same criteria as for the proband. Family members under the age of 7 years were not included. 
GENOTYPING

Among familial cases of PNE we identified 16 Swedish two and three generation families segregating for the disorder as a dominant trait. In these families the trait showed a high penetrance (approximately $90 \%$ in both sexes). A total number of 76 affected and 72 unaffected family members were sampled for linkage analysis with polymorphic microsatellite markers. The genome search began with the analysis of markers in candidate regions including genes involved in the production and concentration of secondary urine. Examples are the genes for 5-natriuretic peptide precursor $\mathrm{C}$ and 5-hydroxytryptamine receptor $2 \mathrm{~B}$ on chromosome 2 ; the genes for the 5-hydroxytryptamine receptors $1 \mathrm{~B}$ and $1 \mathrm{E}$ on chromosome 6 ; the genes for aquaporin 2, aquaporin 2-like protein, and arginine vasopressin receptor $1 \mathrm{~A}$ on chromosome 12; the gene for neuroendocrine specific protein on chromosome 14; and the gene for arginine vasopressin on chromosome 20 . The search was then extended by choosing additional loci at 10-15 cM intervals covering approximately one third of the genome. In total, 98 polymorphic microsatellite markers with a high informativity (PIC >0.7) were chosen primarily from the Généthon linkage map. ${ }^{16}$ Amplification of genomic DNA with primers end labelled with $\gamma-{ }^{32} \mathrm{P}$ were performed in $10 \mu \mathrm{l}$ volumes containing $20 \mathrm{ng}$ genomic DNA, $1 \mathrm{nmol}$ of each dNTPs, $10 \mathrm{mmol} / 1$ Tris $\mathrm{HCl}$ (pH 8.3), 50 $\mathrm{mmol} / \mathrm{l} \mathrm{KCl}, 1.5 \mathrm{mmol} / 1 \mathrm{MgCl}_{2}$, and $0.2 \mathrm{U}$ of Taq DNA polymerase (Boeringer Mannheim). The PCR products were separated on denaturing polyacrylamide gels and visualised by autoradiography. ${ }^{17}$

\section{STATISTICAL ANALYSIS}

Two point linkage analysis between the phenotype and each of the polymorphic markers tested was performed using the MLINK and ILINK options of the FASTLINK 2.2 package. ${ }^{18-21}$ The analyses were performed assuming an autosomal dominant mode of inheritance with an allele frequency of $0.01-$ 0.1 , equal female to male recombination rates, and a penetrance of 0.9 in both sexes. Different penetrance figures have been used in the

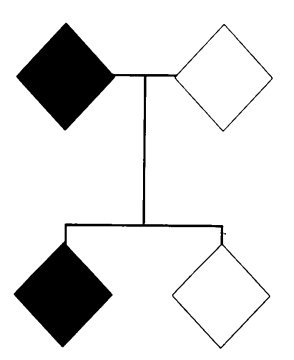

$43 \%($ No $=168)$
B

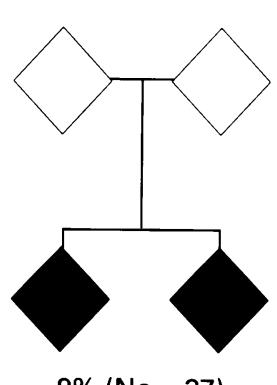

$9 \%($ No $=37)$
C

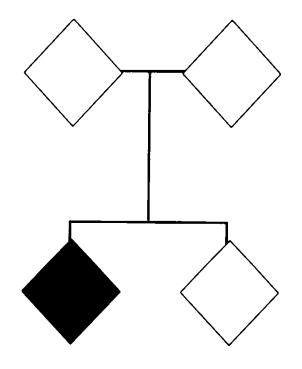

$48 \%($ No $=187)$
Figure 1 Schematic pedigrees representing the distribution of inheritance patterns of PNE in 392 families. The majority (43\%) showed autosomal dominant inheritance $(A)$. Recessive inheritance was consistent in $9.4 \%$ of families $(B)$. Sporadic cases constituted $48 \%$ of the families $(C)$. In $15 \%$ of the sporadic families, a more distant relative (second or third degree) was found with PNE. The possible inheritance from these relatives was not considered because of the expected high phenocopy rate. Dominant genes hidden by reduced penetrance have to be considered in the groups represented by $B$ and $C$. linkage analysis ranging from 0.7 to 0.95 . This affects the results only marginally.

In the screening procedure, families with a positive two point lod score were considered at each locus. The cumulative lod score was calculated and homogeneity testing using the HOMOG1a and HOMOG3R options of HOMOG version $3.33^{2022} 23$ were used to evaluate further the regions of interest. Homogeneity testing was performed for loci where the cumulative lod score in "positive" familes was more than 2. Multipoint analyses in regions of chromosomes $13 \mathrm{q}$ and $12 \mathrm{q}$ were performed using the LINKMAP option of the FASTLINK package. Marker distances of the multipoint maps, with sex average genetic intervals in brackets (cM), were: tel - D13S263 - (4) - D13S291 - cen and tel - D12S368 - (6) - D12S90 - (7) - D12S335 - (8) - D12S80 (11) - D12S81 - (9) - D12S101 - cen, respectively. The numbers of alleles for each marker were reduced to make multipoint calculations possible.

\section{Results}

FAMILY ANALYSES

Of 392 subjects with PNE, 291 were males (74\%) and 101 females (26\%). Family history showed a first degree relative (that is, parent or sister/brother) with the condition in 205 families $(52 \%)$. Of these, 168 had one affected parent which indicates dominant inheritance in $43 \%$ (fig 1). In 37 out of the 392 probands $(9.4 \%)$ the affected first degree relative was either a sister or a brother, compatible with a recessive mode of inheritance (fig 1). In 57 families $(15 \%)$ a more distant family history of PNE was found (second or third degree relative). In the remaining 130 cases, no evidence for a family history of the disorder was found. No clinical differences were found between children with or without a family history.

Genotyping and linkage analysis were conducted in a total of 155 family members from the subgroup of 16 families (fig 2). Of 85 female family members, 44 were affected $(52 \%)$ and of the men 36 were affected out of a total of $70(51 \%)$. Seven obligate carriers were found without a history of the disorder, three of them females and two of them males. In two families the non-penetrant subjects belonged to the grandparental generation (families 12 and 15). Taken together, this corresponds to a penetrance of approximately 0.9 in the 16 families with apparent dominant inheritance and at least three affected members.

\section{LINKAGE ANALYSES}

Regions corresponding to chromosomes 2, 6, $12,13 \mathrm{q}, 14,20$, and 21 were examined. When testing the 16 families for markers closely linked to ENUR1, that is, markers D13S291 and D13S263, suggestion of linkage was found in a subset of the families (families 2,5 , and 9). A cumulative three point lod score of 2.1 was obtained for these three families with markers D13S263 and D13S291 (fig 3, table 1). 

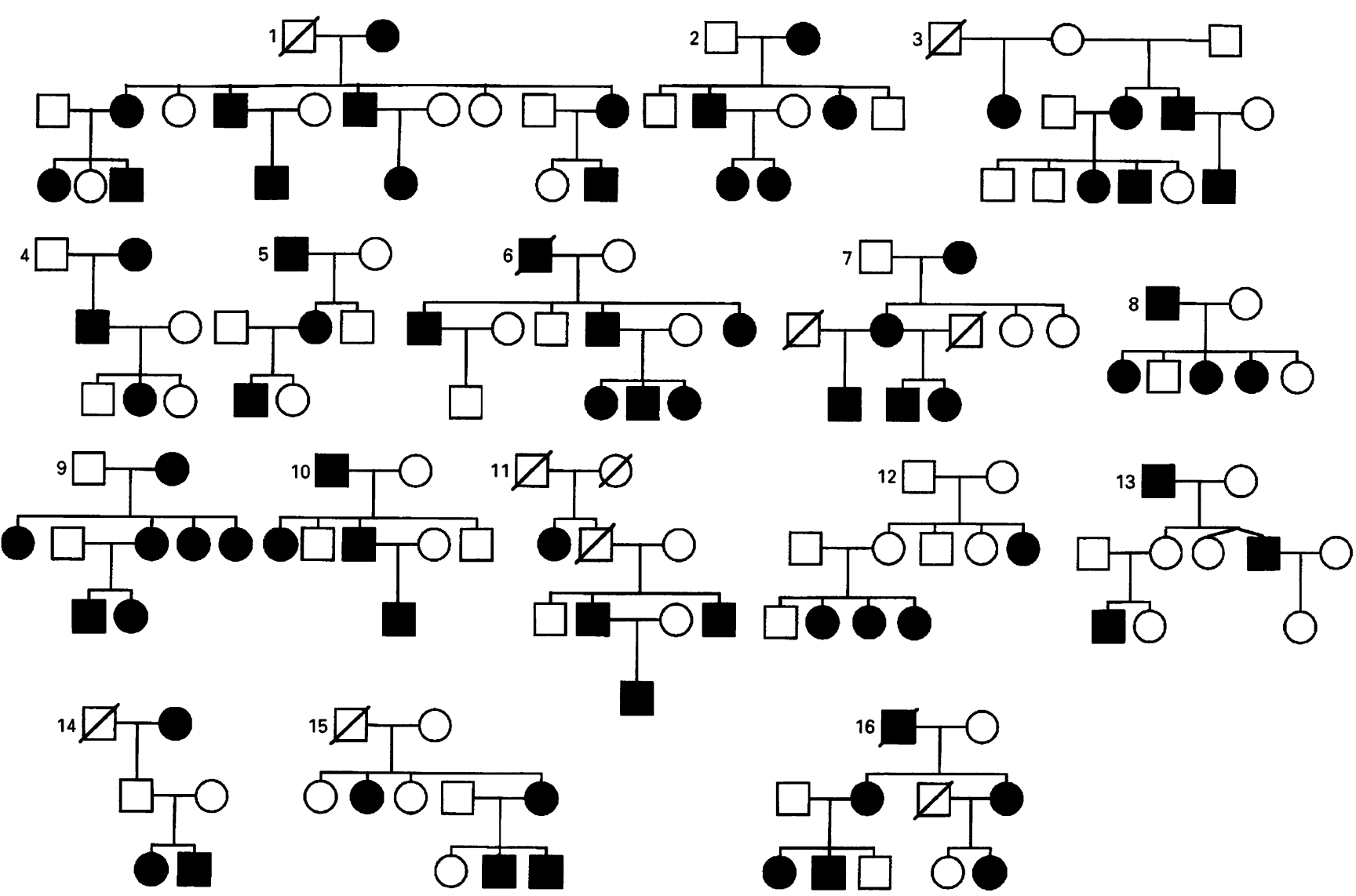

Figure 2 Sixteen families segregating for PNE. The families were selected for linkage analysis as they show a high penetrance with a dominant pattern of inheritance. Reduced penetrance is observed in obligate carriers of families $3,11,12,13,14$, and 15.

Homogeneity testing with HOMOGla on two point data did not give significant evidence for heterogeneity (data not shown). When approximately $35 \%$ of the genome was excluded with a total of 98 polymorphic $(\mathrm{CA})_{n}$ markers, suggestion of linkage to chromosome $12 \mathrm{q}$ was found in a second subgroup of families. A cumulative two point lod score of 4.21 at $\theta=0.05$ from D12S80 was obtained with families having a $Z>0$. A four point linkage analysis with markers D12S335-D12S80-D12S81 and subsequent homogeneity testing with HOMOG 1 a indicated six families $(3-6,11$, and 15) with $>60 \%$ probability of being linked to 12q. The analysis did not show significant evidence for heterogeneity ( $\mathrm{H} 2 v \mathrm{H} 0, \chi^{2}=6.0, \mathrm{~L}$ ratio=20.5). Multipoint analysis of the six families with additional markers in the $12 \mathrm{q}$ region resulted in a $\mathrm{Zmax}$ of 3.88 at $\theta=0.022$ telomeric of D12S80 (table 2). This localises a putative ENUR2 locus probably between D12S80 and D12S81 (fig 4). Family 5 showed indications of linkage to loci on both $13 \mathrm{q}$ and $12 \mathrm{q}$. We then tested for homogeneity using HOMOG3R with three family types, two types linked to $12 \mathrm{q}$ (D12S80) and 13q (D13S291), respectively, and a third type unlinked. The analysis showed indications for linkage and for heterogeneity (difference in $\operatorname{Ln}(\mathrm{L})=3.07$ with a likelihood ratio for heterogeneity $=21.6$ ).

\section{Discussion}

Genetic components behind PNE have been postulated and one gene locus for PNE was recently identified. Our results show that more
Table 1 Three point lod scores between PNE and markers on chromosome $13 q$ (90\% penetrance) in 16 families. The markers span a region of $4 \mathrm{cM}$. The $\theta$ values designate map distances from D13S263 to D13S291 where D13S263 is at map location 0. The maximum cumulative lod score of families 2, 5, and 9 is at map position $4 \mathrm{cM}$ corresponding to D13S291

\begin{tabular}{lrrr}
\hline & \multicolumn{3}{l}{} \\
Family & \multicolumn{1}{l}{$\theta$} & 0.02 & \multicolumn{1}{c}{0.04} \\
\cline { 2 - 4 } 1 & -7.04 & -3.73 & -3.93 \\
2 & 0.42 & 0.46 & 0.47 \\
3 & -0.43 & -0.54 & -0.61 \\
4 & -2.85 & -2.82 & -3.10 \\
5 & 0.82 & 0.78 & 0.76 \\
6 & -0.94 & -1.04 & -1.11 \\
7 & -3.25 & -3.15 & -2.98 \\
8 & -2.57 & -0.45 & -0.26 \\
9 & -0.49 & 0.71 & 0.91 \\
10 & -2.58 & -2.45 & -2.57 \\
11 & -0.16 & -0.12 & -0.10 \\
12 & -3.22 & -1.79 & -1.63 \\
13 & -1.64 & -1.35 & -1.25 \\
14 & -1.33 & -1.28 & -1.33 \\
15 & -5.37 & -1.38 & -0.90 \\
16 & -2.24 & -2.24 & -2.24 \\
Total & -32.87 & -20.39 & -19.85 \\
Zmax families & & & \\
$2,5,9$ & 0.75 & 1.96 & 2.15 \\
\hline
\end{tabular}

than $50 \%$ of all affected children have a family history of the disorder which indicates a strong genetic component. A dominant mode of inheritance was shown in 168 out of 392 cases (43\%) with PNE. Possible recessive inheritance was observed in 37 out of 392 cases (9.4\%). The possibility of reduced penetrance in parents of the "recessive" cases has to be considered as this phenomenon was also observed in highly penetrant dominant fami- 


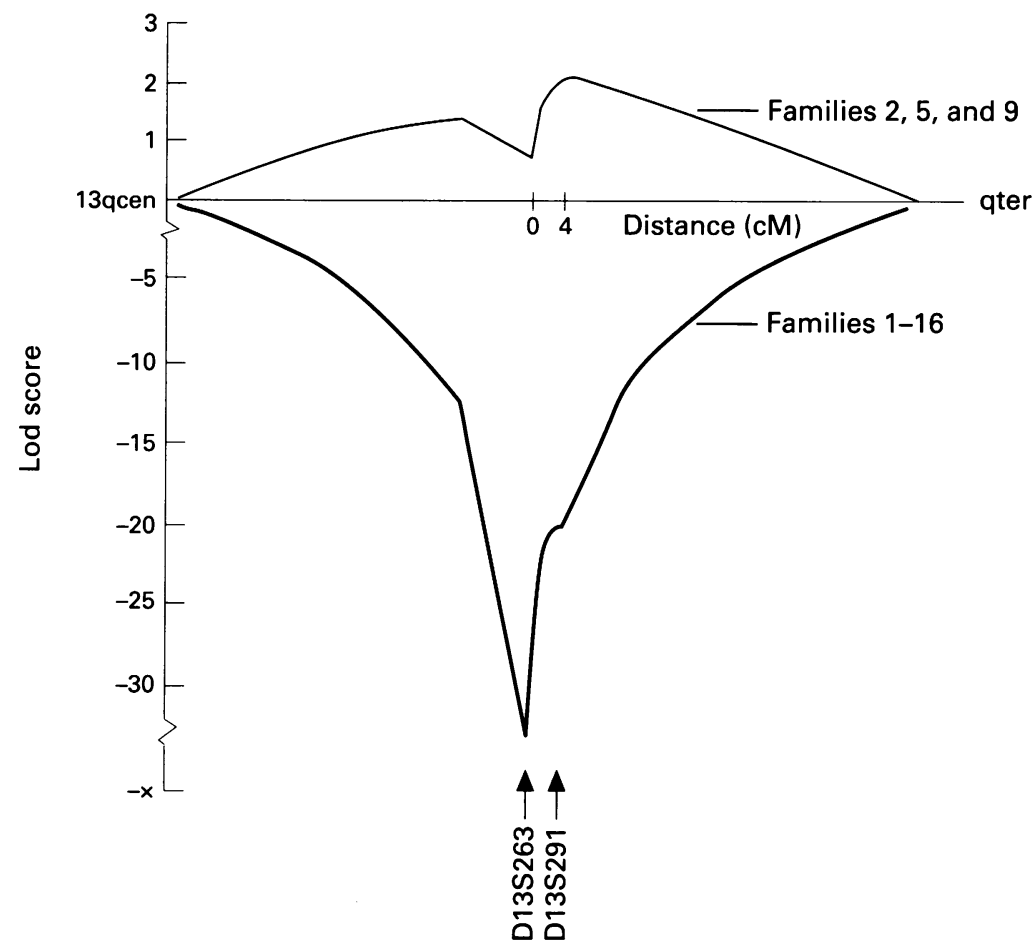

Figure 3 Three point linkage analysis at 13q. The negative curve represents all families (1-16). The positive curve represent the cumulative lod score for families 2,5 , and 9 with a Zmax of 2.15 at D13S291. Map distance 0 (cM) is at D13S236.

lies. No affected first degree relative was observed among $187(48 \%)$ of the cases and these probands were assigned "sporadic". Similarly, reduced penetrance has to be considered in families of sporadic cases for both recessive and dominant inheritance. The overall male to female ratio is $3: 1$ in our material. This indicates sex influenced factors with a higher penetrance in males for inherited genes predisposing to PNE, as suggested in previous studies.

The sporadic cases, accounting for almost $50 \%$ of the patients, might be the result of the additive effect of several genes. This would be expected from the low lambda ratio for the disorder. The ratio (that is, lambda ratio, $\lambda_{r}$ ) is calculated as the incidence in first degree relatives compared to the incidence in the general population, $\lambda_{\mathrm{r}}=((205 / 392) / 0.10)$, which is approximately 5 . This comparatively low $\lambda_{\mathrm{r}}$ is in the same magnitude as for diabetes mellitus type 1 (IDDM) and coeliac disease, ${ }^{2425}$ both regarded as complex genetic diseases.

In contrast, the high penetrance for the disorder observed in certain families favours the existence of major PNE genes in a proportion of the cases. However, the possibility of phenocopies within families has to be considered as the occurrence of PNE in the population is around $10 \%$. It is noteworthy that the predominance among males was not observed in the 16 larger families with a clear dominant pattern of inheritance. Thus, it is possible that certain major PNE genes present in a proportion of families are sex independent, as observed here and also in the previous report by Eiberg et al. ${ }^{14}$

The results from our linkage analyses suggest that six out of 16 families (38\%) are linked to a region restricted by the polymorphic loci D12S368 and D12S101. The sample size was not large enough to obtain significant evidence for heterogeneity with only one group of families linked (HOMOGla). However, when we allowed for different groups of families linked to two different loci, and a third unlinked group, HOMOG3R showed sufficient evidence for a group of families linked to $12 \mathrm{q}$.

Only a few genes have so far been assigned to the D12S90-D12S80 interval including the ones for glucosamine-6-sulphatase, high mobility group proteins (HMGI), gamma interferon, and MDM2. ${ }^{26}$ None of these is a suspected candidate for being involved in PNE but more genes are continuously mapped to this and other parts of chromosome 12. One candidate gene for PNE on chromosome 12 is aquaporin-2 (AQP2) localised at $12 \mathrm{q} 13,{ }^{27}$ but not yet known to be in the D12S90-D12S80 interval. The induction of water reabsorption in the kidneys is mediated by the insertion of AQP2 containing vesicles into the apical membrane of the collecting duct cells. ${ }^{28}$ Since AQP is critically important for urinary concentration

Table 2 Seven point lod scores between PNE and markers on chromosome $12 q$ ( $90 \%$ penetrance). The markers span a region of $41 \mathrm{cM}$. The $\theta$ values designate map distances from D12S368 to D12S101 where D12S368 is at map location 0. The maximum cumulative lod score of families $3,4,5,6,11$, and 15 is at map position 23.2 cM located between D12S80 and D12S81

\begin{tabular}{|c|c|c|c|c|c|c|c|c|c|c|}
\hline \multirow[b]{2}{*}{ Family } & \multicolumn{10}{|l|}{$\theta$} \\
\hline & 0 & 0.05 & 0.1 & 0.15 & 0.19 & 0.232 & 0.25 & 0.3 & 0.36 & 0.41 \\
\hline 1 & -5.43 & -4.91 & -3.94 & -5.34 & -5.84 & -5.50 & -5.15 & -5.06 & -3.85 & -3.67 \\
\hline 2 & -2.27 & -2.27 & -2.38 & -2.38 & -1.78 & -1.14 & -1.11 & -1.12 & -1.27 & -2.16 \\
\hline 3 & 0.17 & 0.26 & 0.32 & 0.22 & 0.26 & 0.08 & -0.17 & -1.14 & -3.28 & -3.53 \\
\hline 4 & 0.82 & 0.81 & 0.80 & 0.82 & 0.82 & 0.79 & 0.77 & 0.71 & 0.66 & 0.62 \\
\hline 5 & -3.13 & 0.37 & 0.75 & 0.82 & 0.82 & 0.74 & 0.63 & 0.29 & -0.08 & 0.02 \\
\hline 6 & -0.64 & -0.52 & -0.46 & -0.46 & -0.44 & 0.65 & 0.83 & 0.85 & 0.74 & -3.46 \\
\hline 7 & -3.27 & -2.21 & -1.89 & -1.74 & -0.71 & -0.42 & -0.59 & -1.28 & -1.30 & -0.95 \\
\hline 8 & 1.12 & 1.12 & 0.80 & 0.14 & 0.17 & 0.18 & 0.18 & 0.15 & 0.13 & 0.12 \\
\hline 9 & -3.04 & -2.63 & -2.33 & -2.88 & -2.86 & -2.76 & -2.66 & -2.73 & -2.62 & -2.43 \\
\hline 10 & -3.85 & -3.80 & -3.16 & -2.63 & -2.57 & -2.85 & -2.73 & -2.97 & -1.45 & -0.88 \\
\hline 11 & -1.89 & 0.61 & 1.01 & 1.11 & 1.10 & 1.04 & 0.98 & 0.83 & 0.17 & -1.89 \\
\hline 12 & -3.27 & -3.23 & -2.75 & -2.72 & -2.94 & -2.53 & -2.12 & -2.01 & -1.94 & -3.09 \\
\hline 13 & -0.62 & -0.62 & -0.64 & -0.65 & -0.64 & -0.64 & -0.63 & -0.62 & -0.64 & -0.69 \\
\hline 14 & -2.08 & -2.07 & -2.07 & -1.79 & -1.38 & -1.30 & -1.30 & -1.30 & -1.26 & -1.09 \\
\hline 15 & -2.91 & -2.20 & 0.24 & 0.44 & 0.41 & 0.59 & 0.58 & 0.57 & 1.19 & 1.38 \\
\hline 16 & -3.95 & -3.66 & -0.54 & -0.15 & -0.25 & -0.82 & -0.89 & -1.62 & -2.87 & -3.95 \\
\hline Total & -34.25 & -24.93 & -16.25 & -17.19 & -15.83 & -13.88 & -13.39 & -16.46 & -17.66 & -25.64 \\
\hline \multicolumn{11}{|c|}{ Zmax families } \\
\hline $3,4,5,6,11,15$ & $5-7.58$ & -0.66 & 2.66 & 2.95 & 2.97 & 3.88 & 3.62 & 2.11 & -0.60 & -6.86 \\
\hline
\end{tabular}




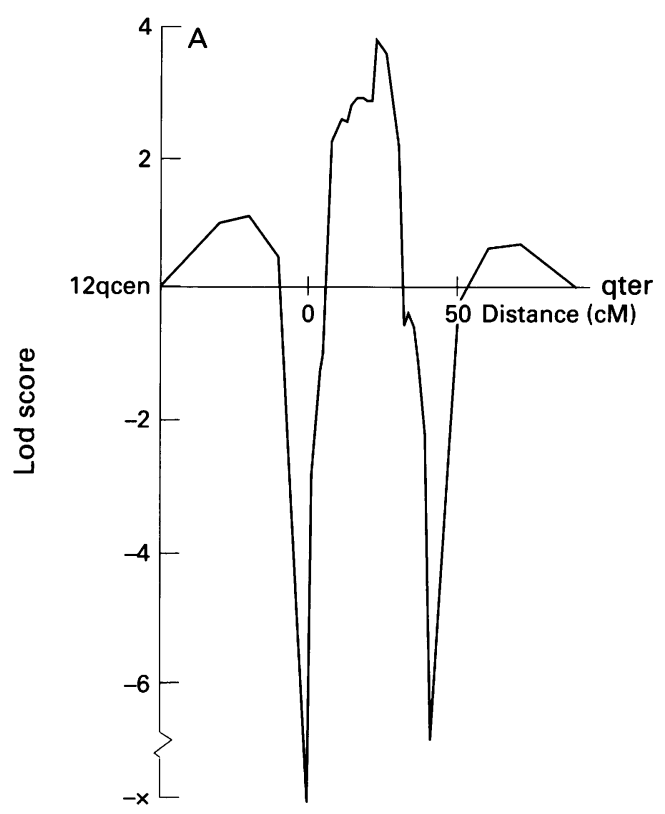

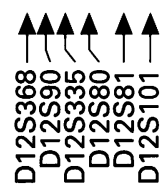

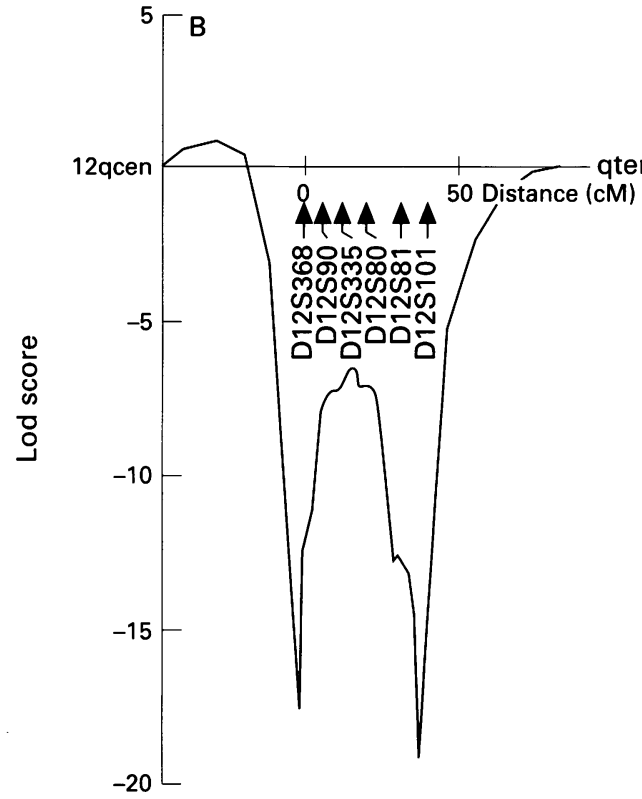

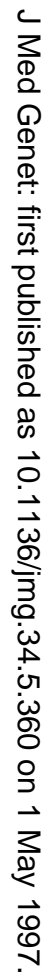

and since a large proportion of enuretics produce an abnormal amount of weakly concentrated urine, it is reasonable to speculate that a defect in this protein would cause enuresis. Interestingly, an analogue to vasopressin (desmopressin acetate) appears to ameliorate enuresis. ${ }^{11} \mathrm{~A}$ more precise localisation of the AQP2 gene is required before considering it as a definite candidate for the disease. Still, it remains unclear how a defect in urinary concentration is connected to the absence of an arousal mechanism, as patients with PNE do not wake up in response to a full bladder.

Recently, linkage analysis of Danish families allowed the assignment of a PNE susceptibility gene to chromosome $13 \mathrm{q}$ in a proportion of families. ${ }^{14}$ Here, we provide additional evidence for genetic heterogeneity and our results suggest the presence of a second locus for PNE on chromosome 12q. Our results also suggest linkage of PNE to the ENUR1 locus at chromosome 13q in another subset of families. At present, we are attempting to refine the position of the gene at $12 \mathrm{q}$ with additional families. Extended genome wide studies and large families are needed in order to identify PNE susceptibility loci further. The identification of gene loci and genes responsible for PNE will uncover the complex genetic basis behind this disorder that affects approximately $10 \%$ of all children. The identification of PNE loci will have direct implications for accurate counselling of parents and for rational trials of therapy.

We wish to thank the Swedish Enuresis Academy for discussion and support. This study was financed by grants from the Swedish Medical Research Council, Queen Lovisa
1 Hallgren H. Enuresis: a clinical and genetic study. Acta Physiol Neurol Scand 1957;32:27-40.

2 Hallgren H. Nocturnal enuresis in twins. Acta Physiol Neurol Scand 1960;35:73-90.

3 Fergusson DM, Horwood LJ, Shannon FT. Factors related to the age of attainment of nocturnal bladder control: an 8-year longitudinal study. Pediatrics 1986;78:884-90.

4 Foxman B, Valdez RB, Brook RH. Childhood enuresis: prevalence, perceived impact, and prescribed treatments. Pediatrics 1986;77:482-7.

5 Jarvelin MR, Vikevainen-Tervonen L, Moilanen I, et al. Enuresis in seven-year-old children. Acta Paediatr Scand 1988;77:148-53.

6 Hellström AL, Hanson E, Hansson S, et al. Micturition habits and incontinence in 7-year-old Swedish school entrants. Eur F Pediatr 1990;149:434-7.

7 Norgaard JP, Djurhuus JC. The pathophysiology of enuresis in children and young adults. Clin Pediatr 1993;9:5-9.

8 Frary LG. Enuresis. A genetic study. Am $\mathcal{f}$ Dis Child 1935;49:557-78.

9 Bakwin H. The genetics of enuresis. Clin Dev Med 1973;48I 49:73-7.

10 Kolvin I, Taunch J, Currah J, et al. Enuresis: a descriptive analysis and a controlled trial. Dev Med Child Neurol 1972; 14:715-26.

11 Hogg RJ, Husmann D. The role of family history in predicting response to desmopressin in nocturnal enuresis. $\mathcal{F}$ Urol 1993;150:444-5.

12 Klackenberg G. Nocturnal enuresis in a longitudinal perspective. A primary problem of maturity and/or a 1981;70:453-7.

13 Jarvelin MR, Moilanen I, Kangas P, et al. Aetiological and precipitating factors for childhood enuresis. Acta Paediat Scand 1991;80:361-9.

14 Eiberg $\mathrm{H}$, Berendt I, Mohr J. Assignment of dominant inherited nocturnal enuresis (ENUR1) to chromosome 13q. Nat Genet 1995;10:354-6.

15 Hjalmaas K. Sweet, the Swedish enuresis trial. Scand 7 Urol Nephrol 1995;173:89-92.

16 Gyapay G, Morissette J, Vignal A, et al. The 1993-94 Genethon human genetic linkage map. Nat Genet 1994;7:246339.

17 Sambrook J, Fritsch EF, Maniatis T. Molecular cloning: a laboratory manual. 2nd ed. Cold Spring Harbor, NY: Cold laboratory manual. 2nd ed. Cold Spring
Spring Harbor Laboratory Press, 1989.

18 Cottingham R Jr, Idury RM, Schaffer AA. Faster sequential genetic linkage computations. Am f Hum Genet 1993;53: 252-63.

9 Schaffer AA, Gupta SK, Shiram K, et al. Avoiding recomputation in linkage analysis. Hum Hered 1994;44:225-37.

20 Ott J. Analysis of human genetic linkage. Baltimore: Johns Hopkins University Press, 1991.

21 Lathrop GM, Lalouel JM. Easy calculations of lod scores and genetic risks on small computers. Am $\mathcal{f}$ Hum Genet 1984;36:460-5. 
22 Ott J. Linkage probability and its approximate confidence interval under possible heterogeneity. Genet Epidemiol Suppl 1986;1:251-7.

23 Morton NE. The detection and estimation of linkage between the genes for elliptocytosis and the $\mathrm{Rh}$ blood type. Am f Hum Genet 1956;8:80-96.

24 Penrose LS. The genetical background of common diseases. Acta Genet Stat Med 1953;4:257-65.

25 Risch N. Assessing the role of HLA-linked and unlinked determinants of disease. Am $\mathscr{f}$ Hum Genet 1987;40:1-14.
26 Marynen P, Kucherlapati R. Report of the third international workshop on human chromosome 12 mapping 1995. Cytogenet Cell Genet 1996;73:1-24.

27 Deen PM, Weghuis DO, Sinke RJ, et al. Assignment of the human gene for the water channel of renal collecting duct aquaporin 2 (AQP2) to chromosome 12 region q12q13. Cytogenet Cell Genet 1994;66:260-2.

28 Deen PM, Verdijk MA, Knoers NV, et al. Requirement of human renal water channel aquaporin-2 for vasopressindependent concentration of urine. Science 1994;264:92-5. 